\title{
Skiing and Snowboarding Injuries in Snow Parks: A Study Based on Self-Reported Practitioners' Statements
}

\author{
Véronique M. Reynier, $\mathrm{PhD}^{1}$; Bastien J. Soulé, $\mathrm{PhD}^{2}$; Johanne M. Pabion-Mouriès, $\mathrm{PhD}^{1}$ \\ ${ }^{1}$ Laboratoire Sport \& Environnement Social (SENS - EA 3742), University Grenoble Alpes, Saint-Martin d'Hères, France; ${ }^{2}$ Laboratoire sur les \\ Vulnérabilités et l'Innovation dans le Sport (L-ViS - EA 7428), University Claude Bernard Lyon 1, Villeurbanne cedex, France
}

\begin{abstract}
Introduction-Snow parks (SPs) are an essential part of what draws individuals to winter resorts. When compared to traditional skiing and snowboarding, SPs heighten the risk and severity of injuries, as well as the rate of hospitalization. The aim of this study is to contribute to the knowledge on accidents in SPs based on the self-reported statements of practitioners.

Methods - A questionnaire measured self-reported accident frequency and type, the nature of injuries sustained, the duration of the discomfort caused, and contributing factors such as terrain features. Demographic and sport-related data, such as ability and frequency of participation, were also collected. The questionnaires were administered in several SPs in the French Alps.

Results-Teenagers and experienced freestylers are most frequently injured. The nature and location of injuries vary depending on the level of practice and type of feature. Few injured participants contact emergency services.

Conclusions-The rate of injuries in SPs exceed that reported in prior research. Because expert and young participants expose themselves to particularly serious bodily impacts in SP, they must pay special attention to prevention.
\end{abstract}

Keywords: freestyle, risks, terrain parks, winter sports

\section{Introduction}

Originating in the United States in the early 1990s, snow parks (SPs) now are an integrated part of winter sports worldwide. They include features made of plastic, metal, wood, and snow with which the SP users interact. These features enable practitioners (a term used to describe skiers and snowboarders) to attempt jumps and acrobatic moves. Jump features (springboards, tables) may be distinguished from flat features (rails, boxes, ramps). SPs generally comprise several zones (slopestyle, big air, rail zone) requiring varying levels of technical knowledge. Initially an alternative practice, freestyling in SPs has gradually become mainstream, and SPs now attract both expert and occasional users. ${ }^{1}$

Corresponding author: Bastien J. Soulé, PhD, University Claude Bernard Lyon 1, Laboratoire sur les Vulnérabilités et l'Innovation dans le Sport, 27-29 Bld du 11 novembre 1918, Campus de la Doua, Villeurbanne 69022, France; e-mail: bastien.soule@ubiv-lyon1.fr.

Submitted for publication February 2019.

Accepted for publication January 2020.
When compared to traditional skiing and snowboarding, these facilities have heightened the risk and severity of injuries ${ }^{2}$ and the hospitalization rate. Confronted with these serious safety issues, winter resorts have adapted their SP management. ${ }^{3}$ Injury research is likely to provide paths for enhancement of prevention. In this regard, most studies are essentially based on data collected from rescue and patrol teams and from mountain resorts' medical centers and hospitals. We first propose a review of the literature, intended to describe the methods put forward in the literature, their limitations, and the main results. We then present a quantitative survey carried out in SPs, directly based on practitioners' statements. The objective was to consolidate knowledge of SP accidents through a subsidiary data-gathering method.

\section{LITERATURE REVIEW}

SPs have caused an increase in the risk of injury compared to traditional slopes ${ }^{4}: 4.6$ accidents for $1000 \mathrm{~d}$ of SP use 
against 2.5 and 3.6 for traditional slope skiing and snowboarding, respectively.

Accident victims in SPs are mostly men (82\%) and young users. ${ }^{5}$ The average age of accident victims is $12^{6}$ to $6 \mathrm{y}^{7}$ lower than it is on traditional slopes, with the 17 to 24 y age group being the most affected. ${ }^{6}$

Expert users are particularly likely to sustain severe injuries in SPs, presumably due to the technical difficulty of their movements and the increased number of jumps they do. ${ }^{8}$ Jumps cause between 56 and $66 \%$ of SP injuries. ${ }^{2,6,9}$ Half of all severe injuries result from jumps, ${ }^{4}$ which are more dangerous than other features such as rails. $^{10-12}$

Overall, $75 \%$ of injuries originate in falls. They do not originate during the jump or other movements, but result from the impact. The main injury mechanism is a fall to the ground from a jump feature, ${ }^{13,14}$ followed by falls from rails or boxes. Technical error is by far the most common reported factor leading to snowboarding injuries. It counts for $81 \%$ of all cases, compared with $14 \%$ for fatigue, $13 \%$ for icy slopes, and $4 \%$ for mistakes made by other users.

Bodily injuries caused by SP accidents are more severe than those on traditional slopes. Evacuation by ambulance is noticeably frequent. ${ }^{8}$ Injury location partially explains this: SP injuries mainly occur to the upper part of the body, whereas accidents on traditional slopes generally affect the lower limbs. Particularly vulnerable body parts (thorax, skull, face, spine, neck) are therefore more frequently affected in SPs. ${ }^{7,15}$ Injuries to the head and spine are twice as common in SPs than on regular ski slopes. ${ }^{6}$ Fifty to $65 \%$ of severe injuries sustained to critical body parts result from poorly controlled landings after jumps (especially big air jumps). ${ }^{16}$ These situations particularly affect the head, ${ }^{17}$ neck, and trunk. Flat features cause comparatively fewer severe injuries. ${ }^{4,7,10}$

Concerning snowboarders, some research ${ }^{8}$ has compared the frequency of serious accidents in SPs and on traditional slopes. Other research ${ }^{11}$ has similarly stated that the risk of head injury for SP users is comparable to that observed on regular slopes. Snowboarders are likewise evacuated by ambulance less often than skiers, given that their lower limbs are affected less frequently. ${ }^{8}$ The same authors nonetheless confirm the particularly high risk of severe upper body injury for snowboarders in SPs.

\section{Methods}

The questionnaire was intended to measure the frequency of injury, to identify the nature of injuries and the duration of discomfort caused, and to understand the accident circumstances (feature type and difficulty).
The difficulty of the features ranges from easy, intermediate, and difficult to very difficult. The questionnaire also included questions regarding sociodemographic (age, sex) and sport-related (activity, frequency, level) characteristics of the interviewees. Their technical level ranges from beginner (small straight jump, relatively wide rail), to intermediate (jump containing a rotation or straight jump of great amplitude), to advanced (jump with multiple rotations), to expert (several rotations on several axes). The questionnaire is included as an appendix to this article (see online Appendix).

The results presented in this article are based on a broader survey rooted in the humanities and social sciences (HSS). In France, HSS research is not required to submit methodically its projects to an ethics committee. We have nevertheless ensured that this work respects the ethical standards of HSS research. This study was approved by a peer committee via the scientific council of the MAIF Foundation, which supported the research. The MAIF Foundation is recognized as being of public utility by the French Minister of the Interior.

Questionnaires were administered in several SPs on a voluntary basis while participants used the lifts or took breaks at rest areas. This context made it impossible to obtain systematically the consent of the parents of minors because in these venues the vast majority of young people are not accompanied by their parents. In such circumstances, the French national commission on information and liberty recommends guaranteeing immediate, absolute, and definitive anonymity of the respondents. We complied with this recommendation. In addition, we informed all participants of both the scientific nature of the project and the use the research team would make of collected data.

\section{BUILDING THE SAMPLE GROUP}

To create a sample group that best represented SP users in the French Alps, different types of resorts and SPs (a total of 12, located in the Isère, Savoie, Haute-Savoie, and Hautes Alpes departments) were included in the study. The $20 \mathrm{~d}$ spent administering the questionnaires were chosen to cover school holidays, term time, weekends, and weekdays. Children under $10 \mathrm{y}$ of age were not interviewed.

Nine hundred eighteen people were surveyed in 12 SPs. They completed the questionnaire in the presence of an interviewer, who could remove any doubts about the proper understanding of the questions. Filling out the questionnaire lasted $10 \mathrm{~min}$ on average. One third of questionnaires were excluded from the analysis because they were filled in by people who go into SPs but do not use features. As a consequence, 638 questionnaires were analyzed. 
Table 1. Sample presentation

\begin{tabular}{|c|c|}
\hline Characteristics & $\%$ \\
\hline \multicolumn{2}{|l|}{ Sex } \\
\hline Male & 90 \\
\hline Female & 10 \\
\hline \multicolumn{2}{|l|}{ Age group (y) } \\
\hline $10-14$ & 21 \\
\hline $15-18$ & 31 \\
\hline $19-24$ & 27 \\
\hline $25+$ & 21 \\
\hline \multicolumn{2}{|l|}{ Practitioner level } \\
\hline Beginner & 22 \\
\hline Intermediate & 44 \\
\hline Advanced & 20 \\
\hline Expert & 14 \\
\hline \multicolumn{2}{|c|}{ Declared injury during the activity } \\
\hline Yes & 53 \\
\hline No & 47 \\
\hline \multicolumn{2}{|c|}{ Declared injury last season } \\
\hline Yes & 21 \\
\hline No & 79 \\
\hline \multicolumn{2}{|c|}{ Overall number of declared injuries during SP activity } \\
\hline$<5$ & 66 \\
\hline $5-10$ & 21 \\
\hline$>10$ & 13 \\
\hline \multicolumn{2}{|l|}{ Sport } \\
\hline Snowboard & 34 \\
\hline Ski & 63 \\
\hline Other $^{\mathrm{a}}$ & 3 \\
\hline
\end{tabular}

${ }^{a}$ Snowscoot, snowblade (short skis).

\section{STATISTICS}

The variables measured in this study are nominal. When examining the relationship between 2 of them, we used the $\chi^{2}$ test with a significance threshold of 0.05 . Statistics are reported for each specific comparison in the results section. The $\chi^{2}$ being a nonparametric tool, it only gives evidence of the presence or absence of association; it does not provide effect estimates and confidence intervals.

\section{Results}

\section{SAMPLE CHARACTERISTICS}

Table 1 describes the sample of surveyed SP users.

\section{ACCIDENTALITY}

The majority of users $(53 \%)$ said they had already been injured in SPs. Two users in 10 had been injured in SPs during the previous season. This high accident rate was also the result of a great number of users having been injured several times. Over one-third of the injured participants, representing $16 \%$ of all users, had already injured themselves more than 5 times during their SP activity.

The accident rate was unsurprisingly linked to activity frequency $\left(\chi^{2}[635,3]=25.1, P<0.05\right)$ : Almost one-third of those who engaged in activity more than twice a week were injured during the previous winter season, compared to $12 \%$ for those who did so once a month or only during holidays.

The rate was also linked to practitioner level $\left(\chi^{2}[631,3]\right.$ $=35.2, P<0.05)$. Intermediate-level practitioners injured themselves 3 times more often than beginners, advanced practitioners 4 times more often, and expert practitioners over 5 times more often (injury rate of $37 \%$ during the previous season for the last category). It should be underlined that this relationship persisted at the same frequency of activity. For example, when focusing on those practicing twice a week or more frequently, intermediate-level practitioners injured themselves 2 times more frequently than beginners, advanced practitioners 3 times more frequently, and experts 4.5 times more frequently $\left(\chi^{2}[404,3]=11.3\right.$, $P<0.05)$. We can therefore suggest that the risk of injury increases as the level of expertise increases. The global accident rate in SP is very high: It rises to $83 \%$ for experts, $70 \%$ for advanced, $50 \%$ for intermediate, and $20 \%$ for beginner practitioners.

The accident rate was likewise linked to practitioners' age $\left(\chi^{2}[317,3]=14.0, P<0.05\right)$. The most at risk were those in the 15 to $18 \mathrm{y}$ age group (with a rate of $27 \%$ in the previous season alone), followed by 19 to $24 \mathrm{y}(20 \%)$, and 10 to $14 \mathrm{y}(18 \%)$. Above $25 \mathrm{y}$, the rate dropped to $15 \%$. Those most at risk are 15 - to 18 -y-old advanced and expert practitioners (39\% were injured during the previous season).

Men and women injured themselves in equal proportions $\left(\chi^{2}[637,1]=1.14, P>0.05\right)$, and there was no direct relationship between the type of activity (snowboarding or skiing) and the accident rate $\left(\chi^{2}[631,1]=0.53, P>0.05\right)$.

\section{TRAUMATOLOGY}

Twenty-nine percent of self-reported injuries in our study were contusions, followed by sprains and dislocations $(21 \%)$, fractures $(17 \%)$, muscular injury and tears $(9 \%)$, and finally head injuries (6\%). Almost one-third (31\%) of these injuries caused less than a week of discomfort, $23 \%$ less than a month, and the remaining $46 \%$ at least 1 mo. Injuries to lower limbs are the most common (33\%), followed by injuries to the trunk (28\%), upper limbs (26\%), and then the head and neck (13\%).

There was a strong link between the nature of injury and its location $\left(\chi^{2}[320,18]=194.17, P<0.05\right)$. Sprains concerned essentially lower limbs (mainly the knee); fractures the upper limbs (wrist) and the trunk (collarbone and 


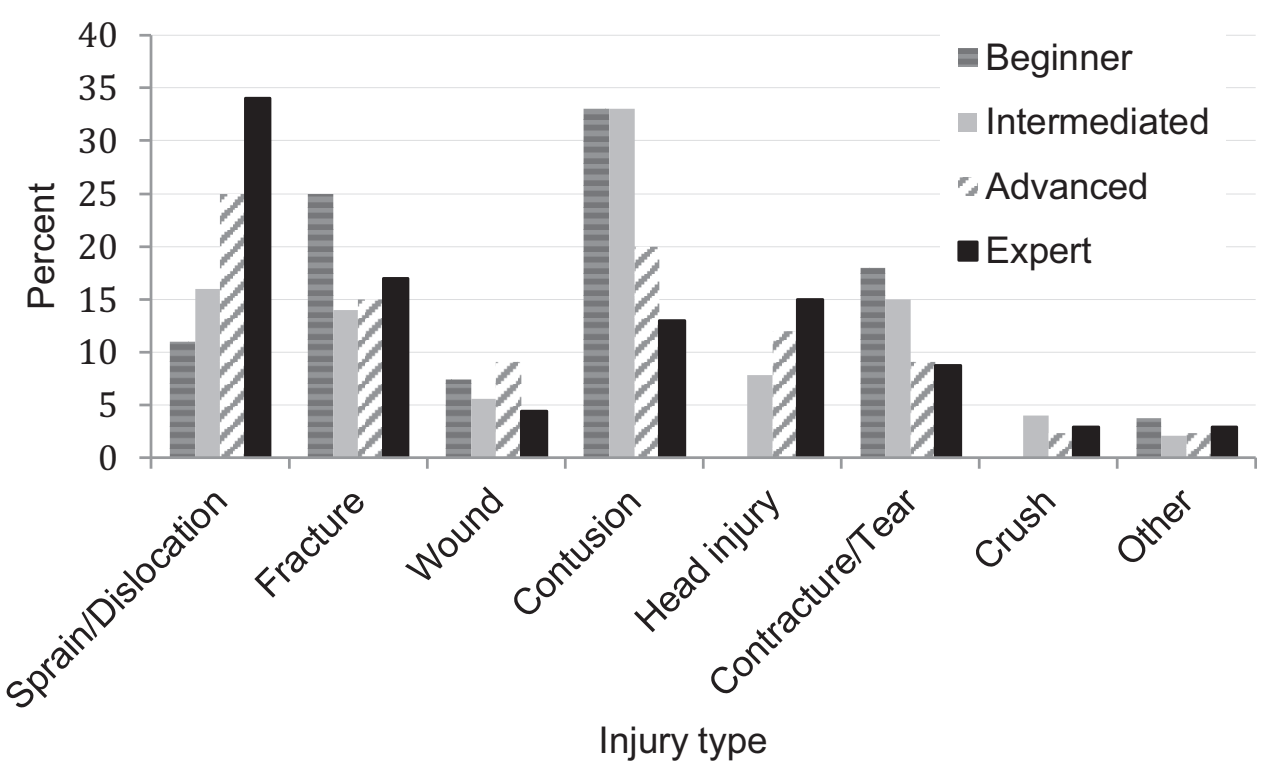

Figure 1. Division of injuries according to type and practitioner level.

ribs); wounds were mainly located on the head; and crush and compression injuries affected the trunk (mainly compressed vertebrae).

The nature of injury likewise depended on level $\left(\chi^{2}\right.$ $[295,15]=27.0, P<0.05)$ : The higher the level, the greater the percentage of sprains and dislocations (34\% of injuries for experts against $11 \%$ for beginners); the relationship was reversed in the case of fractures (17\% vs $26 \%)$. It should also be underlined that the percentage of contusions decreased with increased expertise, whereas that of head injuries rose to $15 \%$ of injuries for expert practitioners (Figure 1).

No relationship existed between activity type and the nature of injury $\left(\chi^{2}[290,5]=6.9, P>0.05\right)$. Injury location, however, differed $\left(\chi^{2}[313,3]=17.6, P<0.05\right)$, with skiers sustaining more injuries to the lower limbs (45 vs $25 \%$ ) and snowboarders to the trunk and upper limbs (61 vs $40 \%)$.

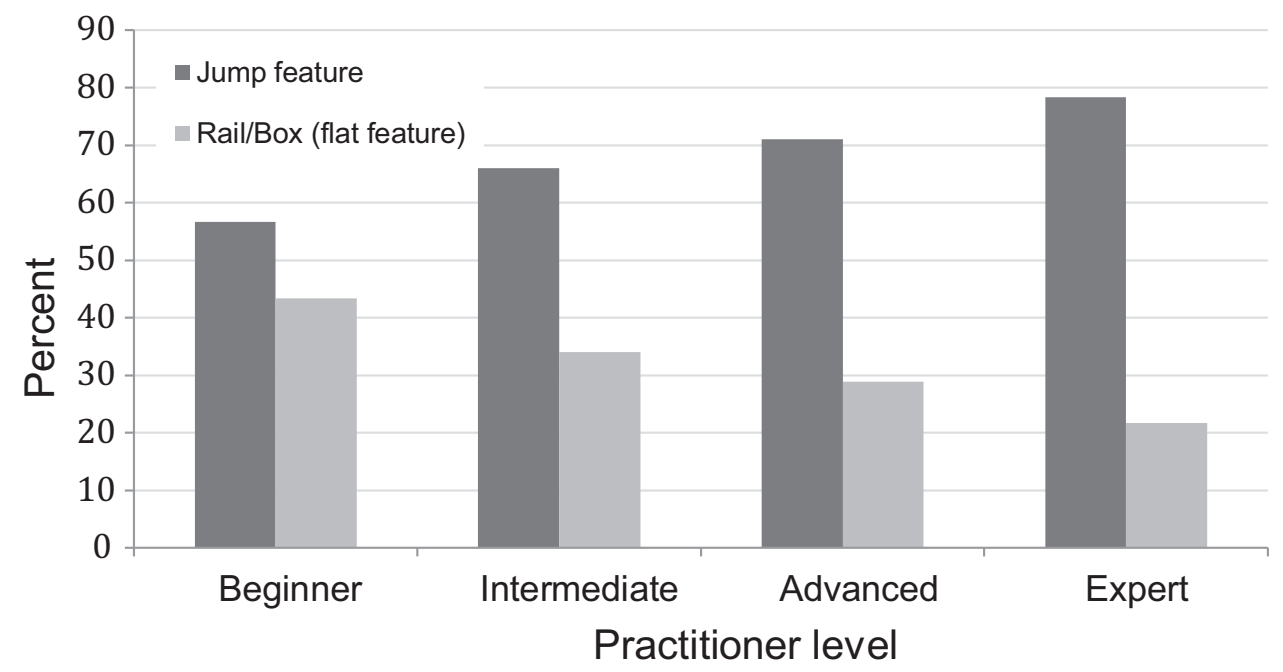

Figure 2. Distribution of injuries according to level and type of feature. 


\section{ACCIDENT CIRCUMSTANCES}

Seven out of 10 accidents in SPs occurred on jumps, a quarter on flat features (eg, rails, boxes), and 5\% outside the features. Forty-two percent of accidents happened on a difficult feature (red) and $35 \%$ on a very difficult one (black). Intermediate-level features (blue) were associated with $14 \%$ of the accidents and easy features (green) $2 \%$.

Most accidents on jumps (84\%) occurred in the landing area, $8 \%$ on kickers (ie, jumping area), and $7 \%$ in flat areas.

\section{VARIATION DEPENDING ON SPORTS LEVEL AND CONTEXT}

On jumps, beginners stood out from other users in that more injured themselves (20\%) by falling on flat ground. There was a relationship between the practitioners' level and the difficulty of feature on which they injured themselves $\left(\chi^{2}\right.$ $[288,9]=58.7, P<0.05)$. Most expert $(62 \%)$ and advanced (47\%) users injured themselves on black features; most intermediate and beginner-level participants were injured on red features (respectively, $54 \%$ and $38 \%$ of the injured). A relationship between the practitioners' level and the type of feature on which they injured themselves was also apparent $\left(\chi^{2}[307,3]=12.9, P<0.05\right)$ : The higher the level of expertise, the lower the risk of accident on flat features (eg, rails, boxes). Indeed, $43 \%$ of beginner victims were injured on this type of feature against $22 \%$ of experts (Figure 2).

Seventy-two percent of accidents in skiing occur on jumps and $25 \%$ on flat features; these percentages are, respectively, $54 \%$ and $38 \%$ for snowboarders $\left(\chi^{2}[302,1]\right.$ $=7.98, P<0.05$ ).

\section{VARIATION DEPENDING ON FEATURE TYPE}

Flat features and jumps caused different types of injuries $\left(\chi^{2}[302,1]=8.0, P<0.05\right)$. The most noteworthy differences were in the overrepresentation of contusions, muscular injuries, tears, and wounds on flat features, and the underrepresentation of sprains, concussion, compression, and crushing. By contrast, injury location did not differ depending on feature type $\left(\chi^{2}[302,3]=2.61\right.$, $P>0.05)$. Finally, injuries on flat features were far from being insignificant; over one-third (38\%) caused discomfort for at least a month (Figure 3).

\section{VARIATION DEPENDING ON FEATURE LEVEL}

Depending on their level of difficulty, jump features could lead to different natures of injuries $\left(\chi^{2}[174,5]=12.8\right.$, $P<0.05)$. We noticed a high proportion of contusions on features of low or intermediate difficulty (37\% of injuries against $14 \%$ for expert-level features), and an overrepresentation of concussions on expert-level features (18\% of injuries against only $2 \%$ for easy and intermediate-level features).

\section{THE USE OF RESCUE SERVICES}

Nineteen percent of SP accident victims called for rescue teams (ski slope rescue); almost one-third of the injured (32\%) (whether rescued or not) went to a resort medical center.

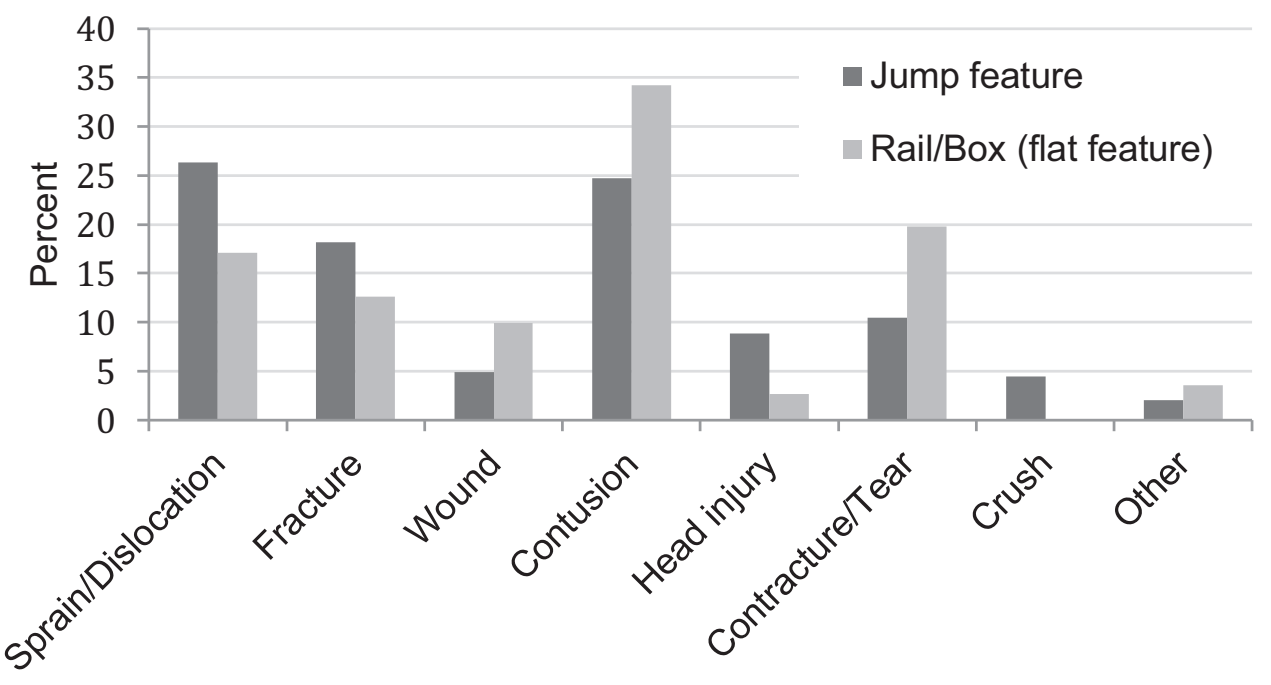

Injury type

Figure 3. Distribution of injuries according to type of injury and feature type. 
There was no sociodemographic or sport-related variable to explain why certain users called rescue teams or went to see resort healthcare professionals. This does depend, however, on the nature of injury $\left(\chi^{2}[297,5]\right.$ $=42.62, P<0.05)$. Forty-five percent of fractures and $35 \%$ of concussions required the intervention of rescue teams, which puts this type of trauma on top in terms of need for assistance. Rescue team intervention likewise depended on injury location $\left(\chi^{2}[320,3]=8.0, P<0.05\right)$ : head and neck injuries were in top position (28\%), followed by injury to the trunk (20\%) and upper (19\%) and lower (14\%) limbs.

\section{Discussion}

Our results complement but also differ from those put forward in the literature. This study confirms that the risk of sustaining an injury in an SP is particularly high: It is greater compared to risk on traditional slopes and increases as level of expertise rises. This strongly contrasts with the situation on traditional slopes, where beginners are particularly at risk of accidents (twice as much as other practitioners). ${ }^{18}$ Overall, risk exposure is higher than the figures found in the literature. This difference can be explained by the fact that in previous studies, no difference was made between those who use the apparatus in SP and "visitors" who simply watch freestylers (one third of people in the $\mathrm{SP}^{19}$ ). This leads to an underestimation of the risk associated with the activity.

In comparison with other studies, our results showed a lower incidence of fractures and head and neck injuries. This difference can be explained by some injuries involving more rescue operations and medical consultations than others. As a result, being based on data collected by ski patrols, medical centers, or hospitals, most studies may overestimate the risk of fractures or head and neck injuries. Such injuries require many more rescue interventions, as well as increased medical care, than required by other form of trauma. Studies based on data collection from health facilities and emergency medical services will generally be biased toward injuries of higher severity, and this may lead to the underrepresentation of injuries to the trunk and upper and lower limbs. These differences also affect the analysis of accident mechanisms and victim profiles because the nature and location of injury may vary depending on skill level, feature type, and activity (snowboarding or skiing).

The managers of winter sports resorts face an uncomfortable situation: They must guarantee both the attractiveness of their SP and security for a very diverse user base. In the 2000s, impressive aerial features flourished to stand out from the competition. Gradually, compromises were made to lower the level of risk and make SPs accessible to the average practitioner. Some areas were designed for beginners (to minimize risks and favor skill development), and others were intended for experts only. Today, risk management mostly relies on information (difficulty of areas, preventive advice, encouragement to wear body protections), the refined and streamlined shaping of features, and adequate momentum before jumps (speed neither too fast nor too slow).

Some recommendations in terms of safety promotion can be drawn from this study. Rather than formulate general messages, it seems necessary to differentiate them according to the technical ability of SP users. Although beginners are the least exposed to the risk of injury, they engage in dangerous behaviors: using features of a too difficult level, not getting enough momentum for a jump, and overexposing themselves on flat features (jibs, rails, boxes). Contrary to aerial features, ${ }^{2}$ most flat features are not impressive at first sight. This can lead beginners, in particular, to underestimate their hazardousness, although they constitute physical obstacles that entail collisions in the event of lowheight falls. Beginners can be targeted by preventive measures quite similar to those usually implemented in winter sports resorts: signage of the features difficulty and warnings based on the highlighted accident-prone behaviors.

In contrast, experts' bodily engagement in SPs inevitably entails accidents. For these freestylers, prevention must challenge preconceived ideas. Indeed, although experts designate beginners and tourists as the main sources of danger in SPs,${ }^{20}$ it would be useful and relevant to remind them that they are by far the most exposed both in terms of accident frequency and injury severity. Unlike in other countries, ${ }^{2}$ helmet usage is suggested but not mandatory in French SPs. Given the nature and location of many injuries, such requirements would not seem overly restrictive, although it might encounter cultural resistance. ${ }^{20}$

This study has a number of limitations. As a retrospective analysis based on the reports of individuals, it is subject to various types of bias: reporting bias, memory bias, and evaluation bias. The very notion of injury can be confusing, whether in terms of severity, location, or type. Moreover, despite the precautions taken in building our sample, we cannot guarantee its representativeness. In brief, our data may be more exhaustive than those originating from rescuers and healthcare services, but the data may also be more subjective. In terms of methods, this self-reported survey highlights the effects of favored sources on numbers and figures and demonstrates the utility of using diversified methodological approaches in injury work to overcome the limits of each protocol.

\section{Conclusions}

This study provides insight into the increased rate of injury among SP users. SPs feature frequent injuries, in proportions that probably exceed those noted in prior research. 
Experts and young participants need special attention in terms of prevention because they expose themselves to particularly serious bodily impacts in these venues. A first step might be to insist on their high exposure to convince them that they are the most at risk in SPs.

Author Contributions: Study concept and design (VR, BS); data gathering and analysis (VR); manuscript writing (VR); drafting and critical revision of the manuscript (BS); data gathering (JPM).

Financial/Material Support: This research was supported by the MAIF Foundation.

Disclosures: None.

\section{Appendix A. Supplementary data}

Supplementary material associated with this article can be found in the online version at: https://doi.org/10.1016/j. wem.2020.01.007.

\section{References}

1. Soulé B, Reynier V, Pabion-Mouriès J. Snow park evolution in France from 1990 to 2010: a plurality of compromises and gradual rationalisation behind a major territorial innovation. Society \& Leisure. 2016:39(1):104-21.

2. Carús L, Escorihuela M. Epidemiology of feature-specific injuries sustained by skiers in a snow park. Wilderness Environ Med. 2016;27(3):415-20.

3. Carús L. Causes of accidents in terrain parks: An exploratory factor analysis of recreational freestylers' views. Wilderness Environ Med. 2014;25(1):94-8.

4. Feuillie B. Incidence de risque de blessure lors de la pratique des sports d'hiver dans les snowparks [dissertation]. Grenoble: University of Grenoble; 2011.

5. Ruedl G, Kopp M, Sommersacher R, Woldrich T, Burtscher M. Factors associated with injuries occurred on slope intersections and in snow parks compared to on-slope injuries. Accid Anal Prev. 2013;50:1221-5.

6. Henrie M, Petron D, Chen Q, Powell A, Shaskey D, Willick $\mathrm{S}$. Comparison of ski and snowboard injuries that occur inside versus outside terrain parks. In: Abstracts of the $19^{\text {th }}$ International Congress on Ski Trauma and Skiing Safety. Keystone, Colorado; 2011.

7. Brooks MA, Evans MD, Rivara FP. Evaluation of skiing and snowboarding injuries sustained in terrain parks versus traditional slopes. Inj Prev. 2010;16(2):119-22.
8. Goulet C, Hagel B, Hamel D, Légaré G. Risk factors associated with serious ski patrol reported injuries sustained by skiers and snowboarders in snow-parks and on other slopes. Can J Public Health. 2007;98(5):402-6.

9. Rainville M, Goulet C, Tremblay T, Maurice P. Blessures en surf des neiges - Portrait des consultations à l'urgence de l'hôpital de l'enfant-jésus de Québec. Québec: Institut National de Santé Publique du Québec, Ministère de l'Education, du Loisir et du Sport. 2010:1-16.

10. Russell K. The Relationship Between Injuries and Terrain Park Feature Use Among Snowboarders in Alberta [dissertation]. Calgary, Canada: University of Calgary; 2011.

11. Russell K, Meeuwisse W, Nettel-Aguirre A, Emery CA, Wishart J, Romanow NT, et al. Characteristics of injuries sustained by snowboarders in a terrain park. Clin J Sport Med. 2013;23(3):172-7.

12. Russell K, Meeuwisse W, Nettel-Aguirre A, Emery CA, Wishart J, Romanow NT, et al. Feature-specific terrain parkinjury rates and risk factors in snowboarders: a case-control study. Br J Sports Med. 2014;48(1):23-8.

13. Zygmuntowicz M, Czerwinski E. The causes of injuries in freestyle snowboarding. Medicina Sportiva. 2007;11(4): 102-4.

14. Pelmont Q. Ski freestyle. Traumatisme des pratiquants experts. Place du masseur kinésithérapute dans la prévention. Research report for state physiotherapist diploma. Genoble: University Grenoble 1; 2013.

15. Audema B, Laporte JD, Constans D. Accidentologie des snowparks. Journal Européen des Urgences. 2007;20(1):35.

16. Mc Neil JA, Swedberg AD. Designing tomorrow's snow park jump. Proc Inst Mech Eng P J Sport Eng Technol. 2012;15: $1-20$.

17. Greve MW, Young DJ, Goss AL, Degutis LC. Skiing and snowboarding head injuries in 2 areas of the United States. Wilderness Environ Med. 2009;20(3):234-8.

18. Laporte JD. L'accidentologie dans les snowparks. e-Cahiers de l'ENSM. Pôle expertise de l'ENSM. Chamonix. 2011;2: 95-8.

19. Reynier VM, Soulé B, Pabion-Mouriès JM. Prévention des risques en snowpark: observation des usages, analyse des formes d'engagement corporel, étude des représentations et formulation de préconisations. Research report. Paris: MAIF Foundation; 2014.

20. Pabion-Mouriès J, Reynier V, Soulé B. The bodily engagement of snow parks freestylers: a study in three French winter sports resorts. Int Rev Sociol Sport. 2016;51(5):581-95. 